\title{
Usefulness of the polymerase chain reaction for monitoring cure of mice infected with different Trypanosoma cruzi clonal genotypes following treatment with benznidazole ${ }^{\text {is }}$
}

\author{
Claudia Tiemi Miyamoto ${ }^{\mathrm{a}, \mathrm{b}}$, Mônica Lúcia Gomes ${ }^{\mathrm{a}, \mathrm{b}}$, Aline Vansan Marangon ${ }^{\mathrm{a}}$, \\ Silvana Marques de Araújo ${ }^{\mathrm{a}, \mathrm{b}}$, Maria Terezinha Bahia ${ }^{\mathrm{c}}$, Olindo Assis Martins-Filho ${ }^{\mathrm{d}}$, \\ Marta de Lana ${ }^{\mathrm{e}}$, Max Jean de Ornelas Toledo ${ }^{\mathrm{a}, \mathrm{b}, *}$ \\ ${ }^{a}$ Departamento de Análises Clínicas, Centro de Ciencias da Saude, Universidade Estadual de Maringá (UEM), Av. Colombo, 87020-900 Maringá, Paraná, Brazil \\ ' Programa de Pós-graduação em Ciências da Saúde, UEM, Maringá, Paraná, Brazil \\ ${ }^{\mathrm{C}}$ Departamento de Ciências Biológicas, Instituto de Ciências Exatas e Biológicas, Universidade Federal de Ouro Preto (UFOP), Minas Gerais (MG), Brazil \\ ${ }^{\mathrm{d}}$ Centro de Pesquisa René Rachou, Fundação Oswaldo Cruz, Belo Horizonte, MG, Brazil \\ e Departamento de Análises Clínicas, Escola de Farmácia, UFOP, Ouro Preto, MG, Brazil
}

\section{A R T I C L E I N F O}

\section{Article history:}

Received 24 October 2007

Received in revised form 3 March 2008

Accepted 25 April 2008

Available online 1 May 2008

Index Descriptors and Abbreviations:

Trypanosoma cruzi

Cloned stocks

DNA, deoxyribonucleic acid

$\mathrm{PCR}$, polymerase chain reaction

Cure control

FBE, fresh blood examination

$\mathrm{HC}$, hemoculture

ELISA, enzyme-linked immunosorbent assay

ALTA, anti-live trypomastigote antibodies

Chagas disease

Murine model

TC, treated and cured

DIS, treated dissociated

$\mathrm{NC}$, treated non-cured

$\mathrm{BZ}$, benznidazole

\section{A B S T R A C T}

The capacity of the polymerase chain reaction (PCR) to detect the DNA of Trypanosoma cruzi was evaluated in 90 blood samples from BALB/c mice infected with T. cruzi cloned stocks of genotypes 19 and 20 ( $T$. cruzi I) and 39 and 32 (T. cruzi II), and treated with benznidazole. The results from the fresh blood examination, hemoculture, and ELISA allowed to group the treated animals into: cured (TC), dissociated (DIS) and non-cured (NC). The PCR detected T. cruzi DNA in 50.9\%, 58.3\% and $100.0 \%$ of the samples from TC, DIS and NC mice, respectively. These DNA possibly derives from live T. cruzi or from recently lysed parasites, suggests that these animals are in fact not cured. The difference between the PCR results and results obtained using other techniques was statistically significant and independent of the parasite genotype. The PCR described has therefore potential to be used in cure control of treated patients.

(c) 2008 Elsevier Inc. All rights reserved.

\section{Introduction}

Chagas' disease, caused by the protozoan parasite Trypanosoma cruzi, affects about 15 million people in the Americas, and is a serious public-health problem in many Latin American countries (Vinhaes and Schofield, 2003). The drugs most frequently used for specific treatment of Chagas' disease are nitroheterocyclic compounds such as nifurtimox nitrofuran (Lampit, Bayer) and nitroim-

\footnotetext{
PCR for detection of T. cruzi in treated mice.

* Corresponding author. Address: Departamento de Análises Clínicas, Centro de Ciencias da Saude, Universidade Estadual de Maringá (UEM), Av. Colombo, 87020900 Maringá, Paraná, Brazil. Fax: +55 214432614490.

E-mail address: mjotoledo@uem.br (M.J. de Ornelas Toledo).
}

idazole benznidazole (Rochagan, Roche); their activity was discovered empirically more than three decades ago. Both chemotherapeutic agents, when administered during the acute phase of the disease, cure $50-70 \%$ of the patients. However, both have limited efficacy in treating the chronic phase of the infection (Castro, 1993).

Natural populations of $T$. cruzi show a pattern of long-term clonal evolution, although genetic recombination events can occur (Tibayrenc and Ayala, 1988; Gaunt et al., 2003). This species is divided into two main phylogenetic lineages: T. cruzi I and T. cruzi II (Anon, 1999). According to the proposed nomenclature, the major genotypes 19 and 20 belong to the T. cruzi I group, and the major genotypes 39 and 32 are classified as T. cruzi II. Several reporters have experimentally demonstrated a significant association 
between genetic distance and biological differences, both in vitro (Laurent et al., 1997; Revollo et al., 1998) and in vivo (Lana et al., 1998; Toledo et al., 2002). Their results emphasize the importance of taking into account the phylogenetic diversity of $T$. cruzi genotypes in all applied studies dealing with diagnosis and treatment of Chagas' disease.

Post-therapeutic monitoring in the chronic phase of Chagas' disease still constitutes a major challenge, because of the long-term persistence of the specific antibodies that are detected by conventional serology (Solari et al., 2001). Furthermore, the parasitological methods, xenodiagnostic and hemoculture, have low sensitivity (Chiari, 1992; Junqueira et al., 1996). In this context, the polymerase chain reaction (PCR) appears to have potential for the diagnosis of human Chagas' disease, and has shown positivity varying from 44.7 to 100\% (Ávila et al., 1993; Britto et al., 1995; Coura et al., 1996; Gomes et al., 1998; Marcon et al., 2002; Castro et al., 2002). This technique is also being tested for monitoring etiologically treated chagasic patients (Solari et al., 2001; Britto et al., 2001; Meira et al., 2004; Zulantay et al., 2004).

It has been suggested that the variability among isolates of $T$. cruzi, together with the immunogenetic characteristics of the host, may influence the outcome of serological tests (Luquetti et al., 2003). Contradictory results between the parasitological and serological techniques may also be related to this variability. A recent publication reported that the PCR showed $100 \%$ of positivity in detecting $T$. cruzi in mouse blood, independently of the genetic constitution of the parasite and the phase of infection (Miyamoto et al., 2006). This high sensitivity of the PCR was obtained with a protocol in which $4.5 \%$ polyacrylamide gel was used. This being so, it becomes imperative to assess the role of the PCR in evaluating the efficacy of the treatment, in view of the genetic diversity of the parasite. The present study proposed to evaluate the capacity of this technique to detect T. cruzi DNA in the blood of mice experimentally infected with cloned stocks of different genotypes, and then treated etiologically with benznidazole (BZ).

\section{Materials and methods}

\subsection{Parasites}

Blood samples previously obtained from BALB/c mice experimentally infected with $18 \mathrm{~T}$. cruzi cloned stocks, belonging to the four main ubiquitous genotypes $19,20,39$, and 32 , and isolated from different hosts and eco-geographical areas of Latin America, were evaluated (Tibayrenc and Ayala, 1988). Four stocks belonging to genotype 19 (Cutia cl1, Gambá cl1, 13379 cl7 and OPS21 cl1), five stocks of genotype 20 (SO34 cl4, Esquilo cl1, P11 cl3, P209 cl1 and Cuíca cl1), four stocks of genotype 39 (Bug2149 cl10, SC43cl1, Mn cl2 and SO3 cl5), and five stocks of genotype 32 (MAS cl1, MVB cl8, CBB cl3, IVV cl4 and Tu18 cl2) were used.

\subsection{Inoculation and treatment of the animals}

Groups of 10 female BALB/c mice, weighing $18 \mathrm{~g}$, were inoculated intraperitoneally with a standard inoculum of 10,000 blood trypomastigotes/animal of each stock (Brener, 1962). These animals were treated with the nitroimidazole derivative benznidazole (Rochagan, Roche) at $100 \mathrm{mg} / \mathrm{kg}$ body weight, for 20 consecutive days, by the oral route (Filardi and Brener, 1987), during the acute (10 days after infection-d.a.i) and chronic (90 d.a.i) phases of the infection.

\subsection{Monitoring the cure}

The treated animals were subjected to a fresh blood examination (FBE) 2 to 3 days after the end of the treatment, on alternate days. For this $5 \mu \mathrm{L}$ of blood collected from the tail vein was microscopically examined until 60 days after the end of the treatment.

Thirty days after the end of the treatment, blood samples were collected for hemoculture (HC) and for the PCR. HC was carried out according to the technique of Filardi and Brener (1987). Briefly, approximately $0.4 \mathrm{~mL}$ blood collected aseptically from the retroorbital sinus vein was distributed into two tubes, containing $3 \mathrm{~mL}$ of LIT medium each. These tubes were incubated at $28{ }^{\circ} \mathrm{C}$ and examined after 30, 45, 60 and 90 days.

The blood samples for the serological techniques were obtained 3, 6 and 9 months after the BZ treatment. An enzyme-linked immunosorbent assay (ELISA) modified according to Voller et al. (1980) was used. Alkaline antigen of the T. cruzi Y strain obtained in the exponential growth phase in LIT medium, and peroxidase-labeled anti-mouse immunoglobulin $G$ conjugated (Sigma) were used. Samples of serum diluted to 1:40 in phosphate-buffered saline, were examined. The mean absorbance of 10 negative-control serum samples plus 2 standard deviations was used as the cutoff to discriminate positive and negative results.

The treated animals were subsequently divided by Toledo (2001) based on the results of the FBE, HC, ELISA, and in some cases, flow cytometry analysis for anti-live trypomastigote antibodies (ALTA). The following groups were formed: treated and cured (TC); treated dissociated (DIS) and treated non-cured (NC). Similarly to chagasic patients submitted to specific treatment (Kretteli and Brener, 1982), mice were considered as treated dissociated when showed negative FBE, HC and ALTA tests and positive conventional serology (ELISA) after treatment with BZ. ELISA negative seraconversion was observed only 9 months after the successful treatment of the chronic phase, in some survived animals.

\subsection{Samples for the PCR}

The blood samples for PCR were collected 30 days after the end of treatment of the acute phase (AP), that is, on 60th d.a.i, and of the chronic phase (CP) on 140th d.a.i, in each of the groups evaluated. Two hundred microliters of blood from the retro-orbital venous plexus of each animal were added to double the volume of 6.0 M/0.2 M guanidine/EDTA (6.0 M/0.2 M G/E), and stored at room temperature (Ávila et al., 1993).

One week after collection, the lysate was boiled for $7 \mathrm{~min}$ and kept at room temperature. Of a total of 90 samples analyzed, 54 were obtained after treatment of the AP, and 36 after treatment of the $\mathrm{CP}$ of the infection. The results of PCR in not treated animals and non-infected controls can be observed in previous publication of our group (Miyamoto et al., 2006).

\subsection{DNA extraction}

From each sample, $100 \mu \mathrm{L}$ aliquots were taken for DNA extraction according to Wincker et al. (1994) with modifications introduced by Gomes et al. (1998). To the blood samples which coagulated after addition of $6.0 \mathrm{M} / 0.2 \mathrm{M} \mathrm{G} / \mathrm{E}, 150 \mu \mathrm{L}$ of Milli-Q sterile $\mathrm{H}_{2} \mathrm{O}$ was added, and the samples were then allowed to stand at least $24 \mathrm{~h}$ before the extraction. During this phase, for each group of four samples, a negative-control (non-infected mouse blood) and a positive-control (mouse blood infected with the $Y$ strain of T. cruzi) were used (Miyamoto et al., 2006).

\subsection{Polymerase chain reaction}

The PCR was processed by mixing $2 \mu \mathrm{L}$ of the DNA solution from each sample, $10 \mathrm{mM}$ Tris- $\mathrm{HCl}$ ( $\mathrm{pH} 9.0$ ), 0.1\% Triton X-100, $75 \mathrm{mM}$ $\mathrm{KCl}, 3.5 \mathrm{mM} \mathrm{MgCl}_{2}, 0.2 \mathrm{mM}$ of each of the deoxynucleotides (dATP, dCTP, dGTP, dTTP; Sigma Company Ltd.), $1 \mathrm{U}$ of Taq DNA polymerase (Phoneutria), $10 \mathrm{pmol}$ of each primer for $10 \mu \mathrm{L}$ of reaction, fol- 
lowing the protocol of Gomes et al. (1998). We used the primers 121 (5'AAATAATGTACGGG(T/G)GAGATGCATGA3') and 122 (5'GGTTCGATTGGGGTTGGTGTAATATA 3') described by Wincker et al. (1994) which amplify a fragment of 330 base pairs (bp) specific for the variable region of the DNA minicircle of the kinetoplast (k-DNA) of the parasite. Thirty microliters of mineral oil was added to the reaction mixture, and then 35 amplification cycles were applied in a thermocycler (MJ Research, PTC-150). The reaction conditions were: DNA denaturing at $95{ }^{\circ} \mathrm{C}$ for $1 \mathrm{~min}$ (with the initial step 5 min longer), annealing the primers at $65{ }^{\circ} \mathrm{C}$ for $1 \mathrm{~min}$, and extension at $72{ }^{\circ} \mathrm{C}$ for $1 \mathrm{~min}$ (with a $10 \mathrm{~min}$ final step). The amplified DNA was revealed by electrophoresis in $4.5 \%$ polyacrylamide silver stained gel.

As a control for contamination during the process, for each 8 samples, 2 negative and 2 positive original controls from the extraction step, and 1 negative and 1 positive-control for the PCR reaction were added. Also, all the steps were carried out in separate environments, with reagents, material, and apparatus exclusive to each workplace, decontaminated with $4 \%$ sodium hypochlorite and ultraviolet light for 20-30 min before the DNA extraction and the PCR reaction.

In order to exclude the possibility that negative results of the PCR were due to the presence of reaction inhibitors, 10 picograms (pg) of previously extracted $T$. cruzi DNA were added to the negative samples.

\subsection{Statistical analysis}

Cochran's $Q$ test was used to assess whether the degree of positivity of the samples varied according to the techniques used. The chi-square test $\left(\chi^{2}\right)$ was applied for comparisons among the genotypes, groups (TC, DIS and NC), and phases of infection. The program Statistic version 6.0 was used (StatSoft, Inc., 2001).

\section{Results}

We analyzed 90 blood samples from BALB/c mice infected with four stocks belonging to genotype 19, five stocks of genotype 20 , four stocks of genotype 39 and five stocks of genotype 32, and then treated with BZ in both phases of infection. Fifty-three samples were from animals considered cured (TC), 12 samples from dissociated animals (DIS) and 25 samples from non-cured animals (NC).

In $50.94 \%$ (27/53) of the samples from TC mice, T. cruzi DNA was detected by the PCR. The difference between the PCR results and those obtained with the other techniques was significant $(p<0.05)$. In $58.33 \%(7 / 12)$ of the samples of DIS animals, parasite DNA was found. All the blood samples (25) of the NC mice showed a positive PCR (Table 1).

Statistical comparisons among the PCR results for the different groups of treated mice (TC vs NC, TC vs DIS and DIS vs NC), without considering the genotype of $T$. cruzi and the phase of infection, indicated significant differences between the NC group and the others $(p<0.05)$. On the other hand, the PCR positivity did not vary significantly with genotype or with phase of infection (Table 1 ). Fig. 1 shows representative gel of the PCR results from the samples collected from animals infected with cloned stocks of the different genotypes and treated with BZ in both phases of infection.

In the negative PCR samples in which the T. cruzi DNA was added, it was possible to detect bands of $330 \mathrm{bp}$ in the polyacrylamide gel, demonstrating that the negative results were not due to the presence of inhibitors (Fig. 2).

\section{Discussion}

The present study showed that the PCR was sensitive in detecting $T$. cruzi DNA in the blood of etiologically treated mice, independently of the groups studied (TC, DIS and NC), of the parasite genotype, and of the phase of infection in which treatment occurred. This result agrees with those of other investigators who also demonstrated high positivity of PCR in patients with Chagas' disease submitted to specific treatment and who had displayed negative results by other methods, following treatment (Solari et al., 2001; Britto et al., 2001).

In the group of mice that were considered cured (TC) by the traditional techniques (fresh blood examination, hemoculture, ELISA and the ALTA analysis), the PCR detected the presence of $T$. cruzi DNA in $50.94 \%$ of the blood samples, suggesting that they were still infected after the treatment. The difference between the PCR results and the other techniques was significant for this group.

The PCR was positive in $58.33 \%$ of the animals considered dissociated (DIS). In spite of the small number of DIS animals and although there was a significant difference from the NC group, these data suggest that the majority of the animals considered dissociated were also not cured. The question of whether to regard human chagasic patients considered DIS, as actually cured or not, is controversial. Patients with Chagas' disease who showed positive conventional serology after treatment were not considered as cured by some researchers, even when the parasitological tests were negative. Our data tend to support this hypothesis, because T. cruzi DNA was detected in the majority of the DIS animals.

Considering the genotype of the parasite and the phase of infection, the positivity of the PCR did not vary significantly. These results corroborate with those obtained in a previous study, in which groups of mice inoculated in the same conditions used in the present study and which were not treated with BZ were analyzed (Miyamoto et al., 2006). These experiments, together with those of the present study, were thoroughly monitored using negative and positive controls in all stages of the process and the PCR inhibition test, which excludes the possibility of false-positives and false-negatives. Therefore, the results presented here demonstrate the superiority of the PCR over the tests classically used in diagnosis and monitoring the cure of Chagas' disease.

The interpretation of the results from the PCR may also raise questions. The positive result may reflect the detection of the

Table 1

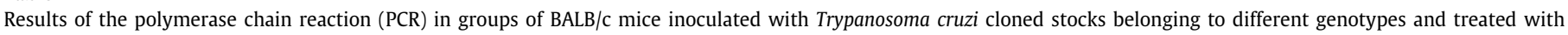
benznidazole $(100 \mathrm{mg} / \mathrm{kg} /$ day, $20 \mathrm{X}$, orally)

\begin{tabular}{|c|c|c|c|c|c|}
\hline Genotype & 19 & 20 & 39 & 32 & Total \\
\hline Group & No. of $+M / T^{d}(\%)$ & No. of + M/T (\%) & No. of $+M / T(\%)$ & No. of + M/T (\%) & No. of $+M / T(\%)$ \\
\hline $\mathrm{TC}^{\mathrm{a}}$ & $11 / 19(57.9)$ & - & $5 / 15(33.3)$ & $11 / 19$ (57.9) & $27 / 53$ (50.9) \\
\hline DIS ${ }^{\mathrm{b}}$ & $1 / 3(33.3)$ & - & $3 / 3(100.0)$ & $3 / 6(50.0)$ & $7 / 12(58.3)$ \\
\hline $\mathrm{NC}^{\mathrm{c}}$ & $2 / 2(100.0)$ & $18 / 18(100.0)$ & $3 / 3(100.0)$ & $2 / 2(100.0)$ & $25 / 25(100.0)^{e}$ \\
\hline
\end{tabular}

a Treated and cured mice.

b Dissociated mice.

c Treated and non-cured mice.

d Number of mice with positive PCR of the total analyzed.

e $p<0.05$ (NC vs TC or DIS). 


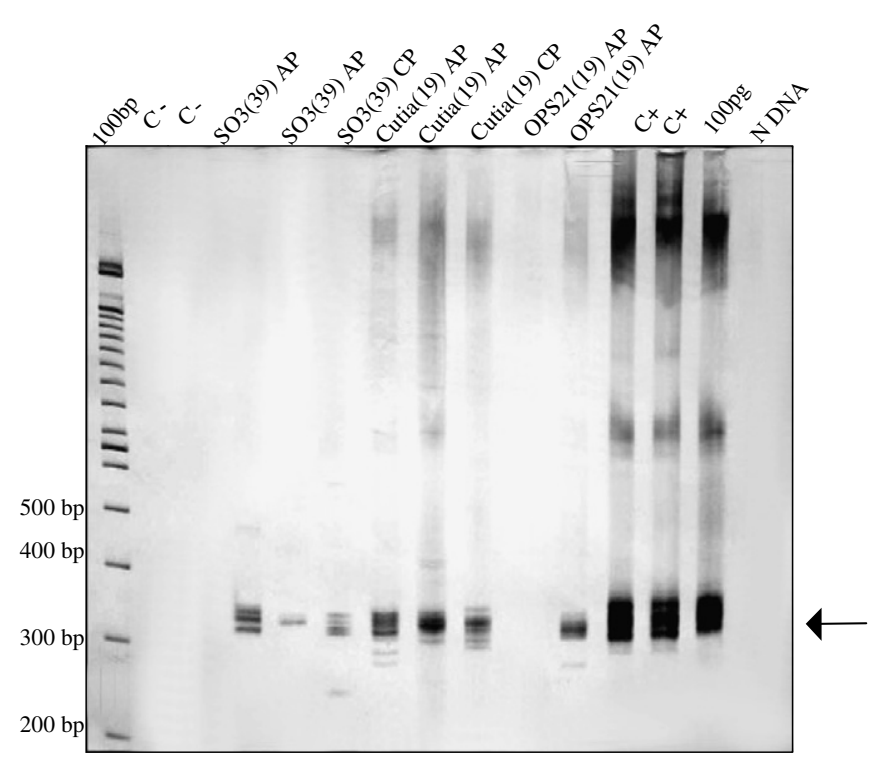

Fig. 1. Polyacrylamide gel showing specific products of $330 \mathrm{bp}$ (indicated by arrow) of the minicircle of the kDNA of Trypanosoma cruzi in the blood of mice infected with cloned stocks of the genotypes 39 and 19, treated with benznidazole in the acute (AP) and chronic (CP) phases of the infection, and not cured (except lane 10). 100 bp: Molecular marker DNA ladder; $C$-: DNA from blood of non-infected mouse; C+: DNA from blood of mouse infected with T. cruzi Y strain; $10 \mathrm{pg}=$ positive-control for the PCR (DNA from T. cruzi 379 strain); N DNA: no DNA in the reaction mixture for the PCR amplification; bp = base pairs.

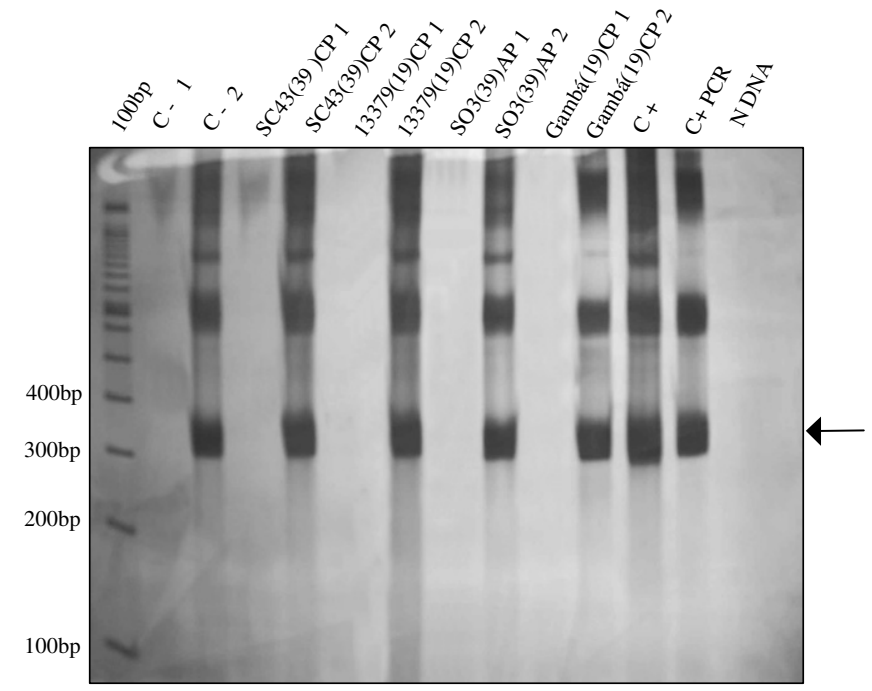

Fig. 2. Polyacrylamide gel showing: (1) blood samples from mice infected with cloned stocks of genotypes 19 and 39, and treated with benznidazole in the acute (AP) and chronic (CP) phases of the infection, and cured. (2) Specific products of $330 \mathrm{bp}$ (indicated by arrow) in the same samples after addition of $10 \mathrm{pg}$ of total DNA of Trypanosoma cruzi. 100 bp: Molecular marker DNA ladder; C- DNA from blood of non-infected mouse; C+: DNA from blood of mouse infected with T. cruzi Y strain; $10 \mathrm{pg}$ = positive-control for the PCR (DNA from T. cruzi 379 strain); N DNA: no DNA in the reaction mixture for the PCR amplification; $b p=$ base pairs.

intact parasite or circulating DNA. However, Tarleton and Zhang (1999) reported that after intramuscular injection with a large quantity of $T$. cruzi kDNA, the PCR in the blood was positive only up to two days after the inoculation. These authors supported the hypothesis that the parasite DNA detected by the PCR is derived from intact, extracellular, or recently lysed parasites.

Published reports on the use of PCR in monitoring the cure in animals infected with $T$. cruzi and treated etiologically are scarce, and do not discuss this subject in depth (Urbina et al., 1996). The high sensitivity of PCR revealed by the results obtained in the present study contrasts with the data of Camandaroba et al. (2003) who noted the difficulty in using this technique as a test for cure in mice, because of the low sensitivity that they observed. In the present study, the technique was evaluated considering not only the genetic diversity of the parasite, but the phase of infection in which the treatment was done. The data presented here serve as a reference for the study of experimental chemotherapy of Chagas' disease and indicate the potential of PCR for post-therapeutic monitoring of chagasic patients.

Furthermore, the sensitivity of the PCR demonstrated here, to detect the presence of $T$. cruzi in treated animals that were considered cured by the classical diagnostic techniques (ELISA and hemoculture), together with other data from the literature (Salomone et al., 2003; Vera-Cruz et al., 2003), allow us to questioner about the reliability of these tests, principally in relation to those used in blood donors screening. Considering the limitations of the methods used as criterion of cure, in human Chagas' disease as well as in experimental $T$. cruzi infection, we were able to observe better sensitivity of the PCR, with rapid detection of the therapeutic failure in BZ-treated mice. However other experiments need to be done for better determinate until when the PCR still remains positive post-treatment before became definitively negative.

\section{Acknowledgment}

To Michel Tibayrenc of the Centre d'Études sur le Polymorphisme des Microorganismes do Institute de Recherche pour le Développement (IRD), Montpellier, France, for providing the stocks of Trypanosoma cruzi.

\section{References}

Anon, 1999. International symposium to commemorate the 90th anniversary of the discovery of Chagas disease 1999. Recommendations from a Satellite Meeting, Rio de Janeiro, Brazil. Memórias do Instituto Oswaldo Cruz 94 (Suppl. I), 429432.

Ávila, H.A., Pereira, J.B., Thiemann, O., Paiva, E., Degrave, W., Morel, C.M., Simpson, L., 1993. Detection of Trypanosoma cruzi in blood specimens of chronic chagasic patients by polymerase chain reaction amplification of kinetoplast minicircle DNA: comparison with serology and xenodiagnosis. Journal of Clinical Microbiology 31, 2421-2426.

Brener, Z., 1962. Therapeutic activity and criterion of cure on mice experimentally infected with Trypanosoma cruzi. Revista do Instituto de Medicina Tropical de Sao Paulo 4, 389-396.

Britto, C., Cardoso, M.A., Vanni, C., Hasslocker-Moreno, A., Xavier, S., Oeleman, W. Santoro, A., Pimez, C., Morel, C.M., Wincker, P., 1995. Polymerase chain reaction detection of Trypanosoma cruzi in human blood samples as a tool for diagnosis and treatment evolution. Parasitology 110, 241-247.

Britto, C., Silveira, C., Cardoso, M.A., Marques, P., Luquetti, A., Macedo, V., Fernandes, O., 2001. Parasite persistence in treated chagasic patients revealed by xenodiagnosis and polymerase chain reaction. Memórias do Instituto Oswaldo Cruz 96 (6), 823-826.

Camandaroba, E.L.P., Reis, E.A.G., Gonçalves, M.S., Reis, M.G., Andrade, S.G., 2003 Trypanosoma cruzi: susceptibility to chemotherapy with benznidazole of clones isolated from the highly resistant Colombian strain. Revista da Sociedade Brasileira de Medicina Tropical 36 (2), 201-209.

Castro, A.M., Luquetti, A.O., Rassi, A., Rassi, G.G., Chiari, E., Galvão, L.M., 2002. Blood culture and polymerase chain reaction for the diagnosis of the chronic phase of human infection with Trypanosoma cruzi. Parasitology Research 88 (10), 894900.

Castro, S., 1993. The challenge of Chagas' disease chemotherapy: an update of drugs assayed against Trypanosoma cruzi. Acta Tropica 53, 83-98.

Chiari, E., 1992. Diagnostic tests for Chagas disease. In: Wendel, S., Brener, Z., Camargo, M.E., Rassi, A. (Eds.), Chagas disease (American Trypanosomiasis): its impact on transfusion and clinical medicine. ISBT, São Paulo, pp. 153-164.

Coura, J.R., Borges-Pereira, J., Alves Filho, F.I., Castro, J.Á., Cunha, R.V., Costa, W., Junqueira, A.C., 1996. Morbidade da doença de Chagas em áreas do sertão da Paraíba e da caatinga do Piauí. Revista da Sociedade Brasileira de Medicina Tropical 29, 197-205.

Filardi, L.S., Brener, Z., 1987. Susceptibility and natural resistance of Trypanosoma cruzi strains to drugs used clinically in Chagas disease. Transactions of the Royal Society of Tropical Medicine and Hygiene 81, 755-759.

Gaunt, M.W., Yeo, M., Frame, I.A., Stothard, J.R., Carrasco, H.J., Taylor, M.C., Mena, S.S., Veazey, P., Miles, G.A., Acosta, N., De Arias, A.R., Miles, M.A., 2003. 
Mechanism of genetic exchange in American trypanosomes. Nature 421 (6926), 936-939.

Gomes, M.L., Macedo, A.M., Vago, R., Pena, S.D.J., Galvão, L.M.C., Chiari, E., 1998. Trypanosoma cruzi: optimization of polymerase chain reaction for detection in human blood. Experimental Parasitology 88, 28-33.

Junqueira, A.C.V., Chiari, E., Wincker, P., 1996. Comparison of polymerase chain reaction with two classical parasitological methods for diagnosis of Chagas disease patients in a northeastern endemic region of Brazil. Transactions of the Royal Society of Tropical Medicine and Hygiene 90, 129-132.

Kretteli, A.U., Brener, Z., 1982. Resistance against Trypanosoma cruzi associated to anti-living trypomastigote antibodies. Journal of Immunology 129, 2009-2012.

Lana, M., Pinto, A.S., Barnabé, C., Quesney, V., Noel, S., Tibayrenc, M., 1998 Trypanosoma cruzi: compared vectorial transmissibility of three major clonal genotypes by Triatoma infestans. Experimental Parasitology 89, 1-5.

Laurent, J.P., Barnabé, C., Quesney, V., Noel, S., Tibayrenc, M., 1997. Impact of clonal evolution on the biological diversity of Trypanosoma cruzi. Parasitology 114 , 213-218.

Luquetti, O.A., Ponce, C., Ponce, E., Esfandiari, J., Schijman, A., Revollo, S., Anez, N., Zingales, B., Ramgel-Aldao, R., Gonzalez, A., Levin, M.J., Umezawa, E.S., Da Silveira, J.F., 2003. Chagas' disease diagnosis: a multicentric evaluation of Chagas Stat-Pak, a rapid immunochromatographic assay with recombinant proteins of Trypanosoma cruzi. Diagnostic Microbiology and Infectious Disease 46, 265-271.

Marcon, G.E., Andrade, P.D., De Albuquerque, D.M., Wanderley, I.S., De Almeida, E.A., Guariento, M.E., Costa, S.C., 2002. Use of a nested polymerase chain reaction (NPCR) to detect Trypanosoma cruzi in blood samples from chronic chagasic patients and patients with doubtful serologies. Diagnostic Microbiology and Infectious Disease 43, 39-43.

Meira, W.S.F., Galvão, L.M.C., Gontijo, E.D., Machado-Coelho, G.L.L., Norris, K.A Chiari, E., 2004. Use of the Trypanosoma cruzi recombinant complement regulatory protein to evaluate therapeutic efficacy following treatment of chronic chagasic patients. Journal of Clinical Microbiology 42 (2), 707-712.

Miyamoto, C.T. Gomes, M.L. Marangon, A.V. Araújo, S.M., Bahia, M.T. Lana, M. Toledo, M.J.O., 2006. Trypanosoma cruzi: sensitivity of the polymerase chain reaction for detecting the parasite in the blood of mice infected with different clonal genotypes. Experimental Parasitology 112, 198-201.

Revollo, S., Oury, B., Laurent, J.P., Barnabé, C., Quesney, V., Carrièrre, V., Noël, S. Tibayrenc, M., 1998. Trypanosoma cruzi: impact of clonal evolution of the parasite on its biological and medical properties. Experimental Parasitology 89, 30-39.

Salomone, O.A., Basquiera, A.L., Sembaj, A., Aguerri, A.M., Reyes, M.E., Omelianuk M., Fernández, R.A., Enders, J., Palma, A., Barral, J.M., Madoery, R.J., 2003.
Trypanosoma cruzi in persons without serologic evidence of disease, Argentina. Emerging Infectious Disease 9, 1558-1562.

Solari, A., Ortiz, S., Soto, A., Arancibia, C., Campellay, R., Contreras, M., Salinas, P., Royas, A., Schinone, H., 2001. Treatment of Trypanosoma cruzi infected children with nifurtimox: a 3 year follow-up by PCR. Journal of Antimicrobial Chemotherapy 48, 515-519.

StatSoft, Inc., 2001. Statistica (data analysis software system), version 6 . www.statsoft.com.

Tarleton, R.L., Zhang, L., 1999. Chagas disease etiology: autoimmunity or parasite persistence? Parasitology Today 15, 94-99.

Tibayrenc, M., Ayala, F.J., 1988. Isozyme variability in Trypanosoma cruzi, the agent of Chagas' disease: genetical, taxonomical, and epidemiological significance. Evolution 42, 277-292.

Toledo, M.J.O., 2001. Comportamento biológico em camundongos de clones de Trypanosoma cruzi pertencentes a diferentes genótipos. Doctoral Thesis. Universidade Federal de Minas Gerais - Belo Horizonte, MG, Brazil.

Toledo, M.J.O., Lana, M., Carneiro, C.M., Bahia, M.T., Machado-Coelho, G.L.L., Veloso, V.M., Barnabé, C., Tibayrenc, M., Tafuri, W.L., 2002. Impact of Trypanosoma cruzi clonal evolution on its biological properties in mice. Experimental Parasitology 100, 161-172.

Urbina, J., Payares, G., Molina, J., Sanoja, C., Liendo, A., Lazardi, K., Piras, M.M., Piras, R., Perez, N., Wincker, P., Ryley, J.F., 1996. Cure of short and long-term experimental Chagas' disease using D0870. Science 273, 969-971.

Vera-Cruz, J.M., Magallon-Gastelum, E., Grijalva, G., Rincon, A.R., Ramos-Garcia, C., Armendariz-Borunda, J., 2003. Molecular diagnosis of Chagas' disease and use of an animal model to study parasite tropism. Parasitology Research 89, 480-486.

Vinhaes, M.C., Schofield, C.J., 2003. Trypanosomiasis control: surmounting diminishing returns. Trends in Parasitology 19, 112-113.

Voller, A., Bidwell, D., Bartlet, A., 1980. Enzyme linked immunosorbent assay. In: Rose, N.R., Friedman, R. (Eds.), Manual of Clinical Immunology. American Society for Microbiology, USA, pp. 359-371.

Wincker, P., Britto, C., Pereira, J.B., Cardoso, M.A., Oelemann, W., Morel, C.M., 1994 Use of a simplified polymerase chain reaction procedure to detect Trypanosoma cruzi in blood samples patients in a rural endemic area. American Journal of Tropical Medicine and Hygiene 51, 771-777.

Zulantay, I., Honores, P., Solari, A., Apt, W., Ortiz, S., Osuna, A., Rojas, A., López, B. Sanches, G., 2004. Use of polymerase chain reaction (PCR) and hybridization assays to detect Trypanosoma cruzi in chronic chagasic patients treated with itraconazole or allopurinol. Diagnostic Microbiology and Infectious Disease 48, 253-257. 